\title{
The Influence of Environmental Cognition on Pro-environmental Behavior: The Mediating Effect of Psychological Distance
}

\author{
Hang $\mathrm{Yu}^{1, a}$, Nan $\mathrm{Ye}^{1, \mathrm{~b},{ }^{*}}$ and Xiao Zhang ${ }^{1, c}$ \\ 1Jiangsu Normal University Business school, Xuzhou, Jiangsu Province, China \\ a1174607211@qq.com, bnye@jsnu.edu.cn, c244785316@qq.com \\ ${ }^{*}$ Corresponding author
}

\begin{abstract}
Keywords: Environmental knowledge, Environmental perception, Media exposure, Psychological distance, Pro-environmental behavior.
\end{abstract}

\begin{abstract}
Based on the data of Chinese General Social Survey (CGSS) in 2010, this paper explores the influence of environmental cognition on citizens' pro-environmental behavior, and introduces psychological distance to explain the mediating mechanism. The results show that environmental knowledge, perception of environmental problems and media exposure all have significant positive effects on pro-environmental behavior. It also reveals that psychological distance plays an intermediary role in the influence of environmental cognition on environmental behavior, that is, environmental protection knowledge, perception of environmental issues and media exposure affect citizens' perception of environmental protection through psychological distance and then influence their environmental behavior. Finally, the paper puts forward the countermeasures and suggestions to improve citizens' environmental behavior based on psychological distance of environmental problems.
\end{abstract}

\section{Introduction}

In recent decades, with the rapid economic development in China, the blue sky and white clouds have gradually disappeared in the line of sight, replaced by air haze, water pollution, ecological imbalance and other environmental problems that seriously affect the quality of life of the people. It is of great significance to make the public more active in choosing environmentally friendly and more sustainable behaviors.

There have been some explanations on the knowing-behavior relationship of environmental protection behavior ${ }^{[1,2]}$. However, the definition of environmental cognition is relatively one-sided, and how can good cognition be transformed into actual behavior needs further research.

In this study, environmental cognition refers to the overall awareness of environment-related issues, including not only one's objective environmental knowledge, but also the subjective perception of environmental issues, also mass media information dissemination will also form a certain degree of environmental cognition. Therefore, this paper divides the environmental cognition into three dimensions, namely environmental knowledge, perception of environmental problems and media exposure, and investigates their influences on public environmental behavior. Besides, we introduce psychological distance into the study as a possible mediating variable to explore the mediating mechanism in environmental cognition and environmental behavior.

\section{Theoretical analysis and research hypotheses}

\subsection{Environmental knowledge and environmental behavior}

Many environmental behavior studies show that knowledge plays an important role in the change of consumer environmental behavior ${ }^{[3]}$. For example, Taufique et al. (2016) found that general knowledge of environmental protection will positively affect consumer attitudes towards the environment and promote consumer behavior of environmental protection ${ }^{[4]}$. Based on the cognitive behavior theory, this paper holds that although the final behavior will be affected by other factors, cognition plays a significant role in the choice of the subject behavior. So, we propose that: 
H1: Environmental knowledge has a positive impact on the public's environmental behavior.

\subsection{Environmental perception and environmental behavior}

The environmental perception refers to the subjective feelings and judgments of the public on the overall severity of environmental problems. Many studies have found that the perception of risk can affect individual behavior and decision-making. Liu et al. (2018) found that subjective understanding of green marked housing is a significant psychological determinant of the intention to use green marked housing ${ }^{[5]}$. Zhang Aiping et al. (2015) found that under the influence of haze pollution, the higher the perception of environmental risk of tourist destination, the more inclined to avoid risky behavior ${ }^{[6]}$. Generally speaking, people who are more aware of the seriousness of environmental problems may be more inclined to choose environmental behavior. So, we assume that:

H2: Environmental perception has a positive impact on the public's environmental behavior.

\subsection{Media exposure and environmental behavior}

Media exposure here refers to the frequency of personal contact with mass media using mobile phones, computers and other devices in daily life, reflecting the amount of information an individual gets from the world. With the development of the Internet, people are getting more and more convenient access to information, access to more and richer media information. In the field of daily life, the more frequently residents are exposed to the media, the more knowledge they acquire about environmental protection, and the more likely they are to adopt environmental behavior ${ }^{[7]}$. This leads to the assumption that:

H3: Media exposure has a positive impact on the public's environmental behavior.

\subsection{The mediating role of psychological distance}

Psychological distance refers to a subjective sense of distance for events within a certain range of psychological space, including time, space, society, probability. Some foreign scholars have pointed out that people's low participation in environmental protection is closely related to their psychological distance to environmental problems ${ }^{[8]}$, and close psychological distance can make individuals more willing to choose environmental protection behavior ${ }^{[9]}$. At the same time, psychological distance is also used as an intermediary variable to explain the psychological mechanism behind consumer behavior ${ }^{[10]}$. The more knowledge an individual has of environmental protection, the more he perceives the environmental problems, and the higher the degree of media exposure, it may further narrow his psychological distance perception of environmental problems, and then promote his choice of environmental behavior. We hypothesize that,

H4: Psychological distance plays a mediating role in the influence of environmental cognition on environmental behavior.

\section{Data and variables}

The data of this study came from CGSS (2010), a comprehensive social survey in China. It covers a wide area, a large number of samples, involving a comprehensive population, with strong authority and authenticity. After excluding the unusable data, we finally get 2381 data to be used in the empirical analysis of this paper.

Explained variable: The environmental behavior is measured by six questions according to the environmental part of CGSS2010, e.g., "do you often go out of your way to sort glass, aluminum cans, plastic, newspapers, etc., for easy recycling?", "do you often go out of your way to reduce fuel consumption in order to protect the environment? "......The assignment of the different options is always, 3; often, 2; sometimes, 1; never, 0 .

Explanatory variables: The environmental knowledge is carried on the appraisal to the ten judgment questions in the CGSS2010 environmental protection part, the correct answer question assignment is 1 , answers wrong or does not answer the question assignment is 0 . The environment perception is measured according to one's own judgment: "on the whole, do you think the 
environmental problems facing China are serious?". The assign values to different options: very serious, 4; more serious, 3; serious and not serious, 2; not too serious, 1; not serious and unable to select, zero. Media exposure is measured by the CGSS2010 A part, of the "past year, you use the media," respectively, including mobile phones, computers, television and other six tools, different options assigned as follows: always, 4; often, 3; sometimes, 2; rarely, 1; never, 0.

The measurement of psychological distance consists of six items in the CGSS2010 environmental section, among which "it is very difficult for a person like me to do anything for environmental protection", "there are more important things to do in life than environmental protection", and "unless everyone else does it, otherwise, my efforts to protect the environment are meaningless "and" environmental problems directly affect my daily life ", which reflect the subjects' different understanding of the relationship between themselves and environmental problems, and belong to the social dimension of psychological distance. "A lot of talk about environmental threats is exaggerated," and "it's hard for me to figure out if my lifestyle is bad or good for the environment". Belongs to the probability dimension of psychological distance. Here, we assign the following values to the different options in the negative statement: completely disagreeing $=1$; comparing disagreeing $=2$; whether or not to agree $=3$; agreeing more $=4$; agreeing completely $=5$. The assignment of positive statements is the opposite of the above. The greater the value is, the farther the psychological distance is, the smaller the psychological distance is.

In addition, we selected gender, age, education level and income as the control variables with reference to relevant literature.

\section{Empirical analysis and Results}

\subsection{Descriptive statistics and correlation analysis}

Descriptive statistical results and correlation coefficients for each variable are shown in table 1 . The environmental knowledge $(M=5.71)$ and perception of environmental issues $(M=2.87)$ are at the median value, indicating that the public's awareness and perception is at an average level at present, but the low media exposure $(\mathrm{M}=1.65)$ indicates that the public is less likely to use mass media to access information. Psychological distance is almost the median, indicating that the public's psychological distance to the environmental issue is in a middle position; while environmental behavior $(\mathrm{M}=1.01)$ is low. It shows that the public seldom practice environmental protection in their daily life.

\begin{tabular}{cccccccc}
\multicolumn{8}{c}{ Table 1. Descriptive statistics and correlation coefficients } \\
\hline variables & Mean & S.D. & $\begin{array}{c}\text { Environmental } \\
\text { knowledge }\end{array}$ & $\begin{array}{c}\text { Environment } \\
\text { perception }\end{array}$ & $\begin{array}{c}\text { Media } \\
\text { exposure }\end{array}$ & $\begin{array}{c}\text { Psychological } \\
\text { distance }\end{array}$ & $\begin{array}{c}\text { Pro-environmental } \\
\text { Behavior }\end{array}$ \\
\hline Environmental knowledge & 5.71 & 2.55 & 1 & & & & \\
Environment perception & 2.87 & 0.97 & $0.225^{* *}$ & 1 & & & \\
Media exposure & 1.65 & 4.46 & $0.397^{* *}$ & $0.199^{* *}$ & 1 & & \\
Psychological distance & 3.60 & 3.78 & $-0.274^{* *}$ & $-0.234^{* *}$ & $-0.303^{* *}$ & 1 & \\
Pro-environmental Behavior & 1.01 & 0.62 & $0.310^{* *}$ & $0.214^{* *}$ & $0.352^{* *}$ & $-0.337^{* *}$ & 1 \\
\hline
\end{tabular}

\subsection{Hypothesis test}

This paper uses multiple linear regression to analyze the main effects of environmental knowledge, perception of environmental issues, and media exposure on environmental behavior. In the regression model, environmental protection knowledge (model 1), environmental perception (model 2), media exposure (model 3), and psychological distance (model 4) are added in turn. The results (see Table 2) showed that the introduction of each variable significantly improved the fitness of the model, indicating that the model fitting is more ideal, each dependent variable has its own explanatory power. Among them, environmental knowledge $(\mathrm{M} 1, \beta=0.058, \mathrm{p}<0.001)$ has a significant positive impact on environmental behavior, $\mathrm{H} 1$ is supported. Perception of environmental problems (M2, $\beta, 0.085, \mathrm{p}<0.001)$ has a significant positive impact on environmental behavior, H2 is supported. Media exposure $(M 3, \beta, 0.032, p<0.001)$ has a significant positive effect on environmental behavior, H3 is supported. 
Table 2. Multiple linear regression analysis

\begin{tabular}{ccccc}
\hline & Model 1 & Model 2 & Model 3 & Model 4 \\
\hline Gender & $0.086^{* *}$ & $0.077^{* *}$ & $0.073^{* *}$ & $0.074^{* *}$ \\
Age & $0.004^{* *}$ & $0.004^{* *}$ & $0.004^{* *}$ & $0.004^{* *}$ \\
Education & $0.029^{* *}$ & $0.025^{* *}$ & 0.006 & 0.003 \\
Income & 0.007 & 0.007 & 0.003 & 0.004 \\
Environmental knowledge & $0.058^{* *}$ & $0.053^{* *}$ & $0.044^{* *}$ & $0.037^{* *}$ \\
Environment perception & & $0.085^{* *}$ & $0.079^{* *}$ & $0.059^{* *}$ \\
Media exposure & & & $0.035^{* *}$ & $0.030^{* *}$ \\
Psychological distance & & & & $-0.034^{* *}$ \\
Adj R2 & 0.130 & 0.146 & 0.183 & 0.220 \\
$\mathrm{~N}$ & 2381 & 2381 & 2381 & 2381 \\
\hline
\end{tabular}

In order to study whether the perception, cognition and media exposure of environmental problems affect the decision of individual's environmental behavior by narrowing the psychological distance between individuals, this study adopts Bootstrap's intermediary test method. First, take environmental knowledge as independent variable, environmental behavior as dependent variable, psychological distance as intermediary variable to test. The results (see Table 3 ) showed that the mediating effect of psychological distance was significant ( $\mathrm{LLCI}=0.0479, \mathrm{ULCI}=0.0665$ ), which played a partial mediating role between environmental cognition and environmental behavior (BootLLCI $=0.0145$,BootULCI $=0.0219$ ). In the same way, psychological distance plays an important role in mediating environmental perception, media exposure and environmental behavior. So H4 is supported.

Table 3. The mediation test result

\begin{tabular}{cccccc}
\hline & effect & LLCl & ULCl & BootLLCl & BootULCl \\
\hline Environmental knowledge & 0.0181 & 0.0479 & 0.0665 & 0.0145 & 0.0219 \\
Environment perception & 0.0453 & 0.0670 & 0.1162 & 0.0363 & 0.557 \\
Media exposure & 0.0106 & 0.0328 & 0.0434 & 0.0086 & 0.0129 \\
\hline
\end{tabular}

\section{Conclusion and discussion}

Based on the data of Chinese General Social Survey 2010, this paper examines the influence of environmental knowledge, perception of environmental issues and media exposure on citizens' environmental behavior. It is found that the higher the level of environmental knowledge, the deeper the perception of environmental issues, and the more exposure with mass media, the more inclined to engage in environmental protection behavior. According to the theory of psychological distance, it revealed that psychological distance plays a part mediating role in the process of environmental cognition's influence on environmental behavior.

Therefore, in order to guide the public to actively carry out environmental protection behavior, it is very important to draw in the psychological distance perception of the public to the environmental problems. In practice, the government should step up its efforts to make the public feel the severity of environmental problems and the importance of environmental protection behavior. At the same time, strengthen the promotion of green and other related concepts, in the attention of the media to vigorously promote environmental protection concepts, environmental protection knowledge, improve people's objective understanding and subjective perception of environmental issues. In addition, we should carry out mass environmental protection activities at the grass-roots level, advocate the establishment of environmental protection non-governmental organizations, and encourage people to actively publicize and participate in environmental protection activities. In a word, it is not a problem that is far away from us in time and space, and it is not a problem that has nothing to do with our rights and interests, so that people can better raise their environmental awareness and promote individual environmental protection behavior to realize the harmonious and sustainable development of social health. 


\section{Acknowledgement}

This research was financially supported by the National Natural Science Foundation of China (Grant NO. 71502072) and the Funds of Jiangsu province postgraduate research innovation project (Grant NO. KYCX17_1610).

\section{References}

[1] Levine, D. S., \& Strube, M. J. (2012). Environmental attitudes, knowledge, intentions and behaviors among college students. Journal of Social Psychology, 152(3), 308-326.

[2] Peng, Y. (2015). Analysis of the influence of urban residents' environmental cognition on environmental behavior. Journal of Central South University (Social Science),21(03):168-174.

[3] Onel, N., \& Mukherjee, A. (2016). Consumer knowledge in pro-environmental behavior: an exploration of its antecedents and consequences. World Journal of Science Technology \& Sustainable Development, 13(4), 328-352.

[4] Taufique, K. M. R., Siwar, C., Chamhuri, N., \& Sarah, F. H. (2016). Integrating general environmental knowledge and eco-label knowledge in understanding ecologically conscious consumer behavior. Procedia Economics \& Finance, 37(2016), 39-45.

[5] Liu, Y., Hong, Z., Zhu, J., Yan, J., Qi, J., \& Liu, P. (2018). Promoting green residential buildings: residents' environmental attitude, subjective knowledge, and social trust matter. Energy Policy, 112, 152-161.

[6] Zhang, A. P., Zhong, L. S., Yong, X., Hui, W., \& Dang, L. J. (2015). Tourists' perception of haze pollution and the potential impacts on travel: reshaping the features of tourism seasonality in beijing, china. Sustainability, 7(3), 2397-2414.

[7] Zhang, P., \& Jin, Y. J. (2016). The impact of mass media on environmental behaviors of urban and rural residents in china and its related affecting mechanism_— based on the data from 2013 chinese comprehensive social survey. Journal of Renmin University of China.30 (04):122-129.

[8] Jones, C., Hine, D. W., \& Marks, A. D. (2017). The future is now: reducing psychological distance to increase public engagement with climate change. Risk Analysis, 37(2), 331-341.

[9] Schuldt, J. P., Rickard, L. N., \& Yang, Z. J. (2018). Does reduced psychological distance increase climate engagement? On the limits of localizing climate change. Journal of Environmental Psychology, 55: 139-146.

[10]Zhou, M. H., Pei-Mei, L. I., Mou, Y. P., \& Management, S. O. (2015). Effects of online reviews on purchase intention of consumers — the mediation of psychological distance. Soft Science. (1):101-104. 